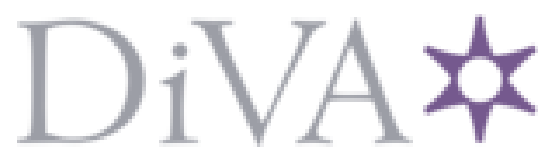

http://www.diva-portal.org

This is the published version of a paper published in International Journal of Life Science and Medical Research.

Citation for the original published paper (version of record):

Koptyug, A., Rännar, L., Bäckström, M., Fager Franzén, S., Dérand, P. (2013)

Additive Manufacturing Technology Applications Targeting Practical Surgery.

International Journal of Life Science and Medical Research, 3(1): 15-24

http://dx.doi.org/10.5963/LSMR0301003

Access to the published version may require subscription.

N.B. When citing this work, cite the original published paper.

Permanent link to this version:

http://urn.kb.se/resolve?urn=urn:nbn:se:miun:diva- 18006 


\title{
Additive Manufacturing Technology Applications Targeting Practical Surgery
}

\author{
Dr. Andrey Koptyug ${ }^{1 *}$, Dr. Lars-Erik Rännar ${ }^{2}$, Dr. Mikael Bäckström³ ${ }^{3}$ M.Sc. Sanna Fager Franzén ${ }^{4}$, DDS Per \\ Dérand $^{5}$ \\ ${ }^{1,2,3}$ Mid Sweden University, Department of Engineering and Sustainable Development, Akademigatan 1, SE-83125, Östersund, \\ Sweden \\ ${ }^{4}$ ARCAM AB, Krokslätts Fabriker 27A, SE-431 37 Mölndal, Sweden \\ ${ }^{5}$ Department of Oral and Maxillofacial Surgery, University Hospital, SE-221 85, Lund, Sweden \\ *1 andrei.koptioug@miun.se; ${ }^{2}$ lars-erik.rannar@miun.se; ${ }^{3}$ mikael.backstrom@miun.se; ${ }^{4}$ sanna.franzen@ arcam.com; \\ 5per.derand@skane.se
}

\begin{abstract}
Present paper is written with the aim to provide an overview of the Additive Manufacturing (AM) technologies in the applications benefiting orthopaedics and prosthetics. To our opinion, modern medicine yet does not fully comprehend existing unique possibilities and emerging opportunities provided by such technologies. Many of the advantages of Additive Manufacturing have been already proven experimentally and are used, but many others tough proven by researchers and method developers are still await to take their rightful place in the arsenal of modern practical medicine. Today the applications of AM technologies are mainly discussed at the specialised forums and in publications targeting the technology specialists. Present paper is written for the existing and potential users of the medical applications of AM technologies. It outlines some of the most interesting achievements of AM technologies along with existing challenges, recent developments and targets for the future.
\end{abstract}

Keywords- Additive Manufacturing; Implant; Cellular; Patient Specific; Reconstruction; Electron Beam Melting; Composites; Surface

\section{INTRODUCTION}

The name Additive Manufacturing (AM) ${ }^{[1-3]}$ describes today a large family of technologies producing components with extremely complex volume shapes. In AM systems, products are manufactured from the materials as different as metal ${ }^{[4-7]}$, plastic ${ }^{[8-11]}$, human tissue and chocolate and cheese ${ }^{[12]}$. Main feature common to these seemingly different technologies is the way components are made, adding layer upon layer of the build material ${ }^{[1,3]}$. Additive manufacturing in plastic and metal is already well established within engineering and technology and is commonly used for rapid prototyping and small series manufacturing, as well as manufacturing of the unique components with complex 3D shapes. One of the rapidly growing application areas of the AM is medicine, especially orthopaedics and prosthetics. These applications are utilizing strongest advantages of the AM technologies such as freedom of component shapes, possibilities of computer optimization of the manufactured-to-be component functionality and properties, and good value for money in manufacturing one-off or small series of products ${ }^{[13]}$. These benefits are already recognized by medical implant manufacturers (see, for example, [14, 15]) and practical surgeons.

In present paper some of the achievements and existing challenges in utilizing AM in medical applications are described, and emerging new possibilities opened by the development of these technologies and material sciences are outlined using the examples of Electron Beam Melting $\left(\text { EBM }{ }^{\circledR}\right)^{[3,4-6]}$ on the additive manufacturing in metal, and Fused Deposition Modelling (FDM $\left.{ }^{\circledR}\right)^{[8]}$ on the additive manufacturing in polymers.

\section{IMAGE TO IMPLANT}

Main advantages of the AM technology are coming from combination of the processing power of modern computers, the advances in the material sciences and high spatial resolution and freedom of "sculpturing" of the shapes provided by the AM technologies. Today one of the rapidly developing application areas of the AM technologies is related to modern medical implant designing and manufacturing. Here one can outline the major stages of the "image-to-product" path as initial medical image manipulation ${ }^{[16-18]}$, generation of the technical CAD design files determining the shapes of parts ${ }^{[19,20]}$, parameter modelling and optimization using these "shape files" $[18,20]$ and finally the manufacturing of chosen designs by the "3D printing" using AM technologies.

Computers are employed for the initial medical image manipulation and design of the matching plastic or metal structures (Fig. 1a, 1b). At this stage, the original image, for example the medical CT or MRI, is "filtered" in order to "remove" the lower density tissue and cartilage leaving the image of the bones (commercial software for such applications is readily available $\left.{ }^{[16,}{ }^{17]}\right)$. This shapedescribing file in turn can be used for manufacturing of the pre-operative bone models using AM technology (Fig. 1c). 

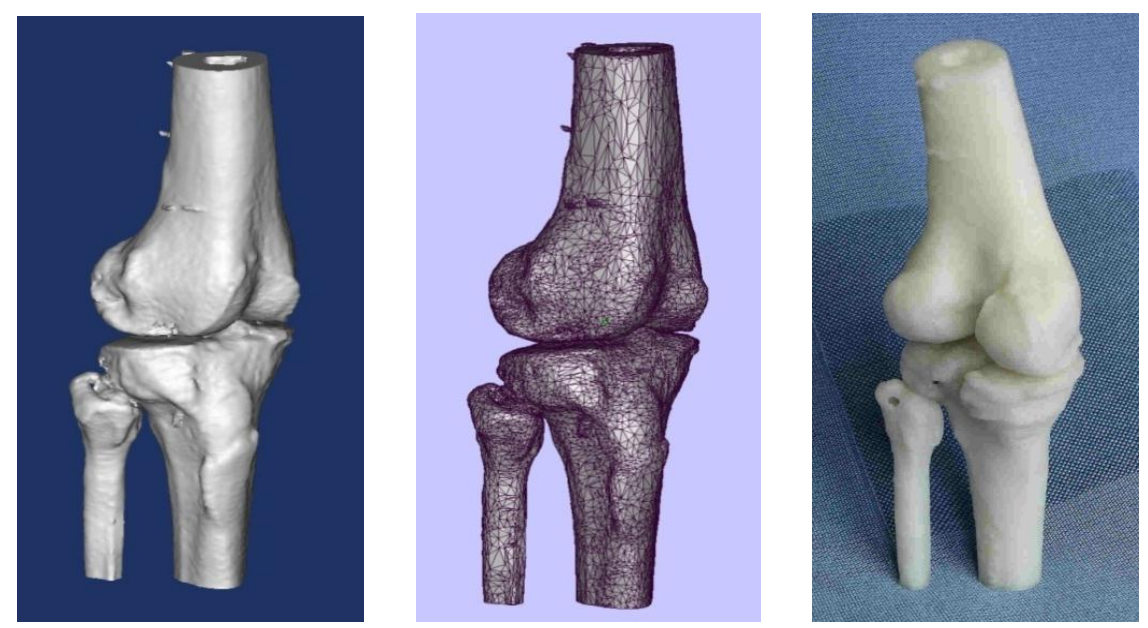

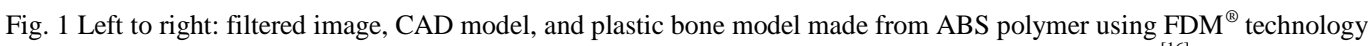
Image processing is done using medical R\&D Software package Mimics by Materialise ${ }^{[16]}$.

Some software products allow quite advanced manipulation of the acquired shape files ${ }^{[16-18]}$. For example, starting from the original image one can virtually take apart the fragments of the shattered bone, realign the pieces that should be spared during the surgery, and design a dedicated metal implant plate with the holes in places where the screws would be put during the actual surgery (Figs. 2, 3).
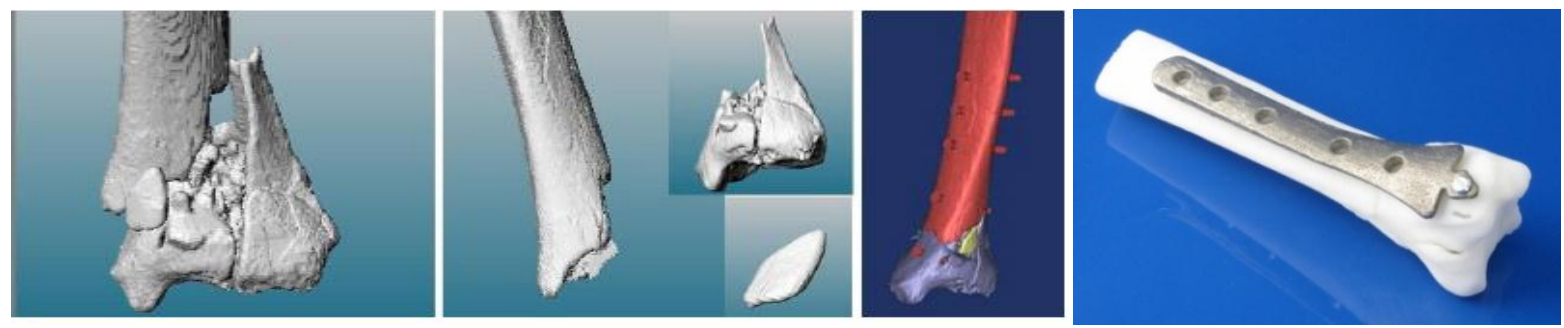

Fig. 2 Left to right: filtered image of the shattered bone; bone fragments; CAD model; plastic bone model made from ABS polymer using FDM with the fixation plate made in $\mathrm{EBM}^{\circledR}$ technology

Image processing is done using medical R\&D Software package Mimics ${ }^{[16]}$. (Courtesy of Marie Cronskär, Mid Sweden University ${ }^{[21]}$ )
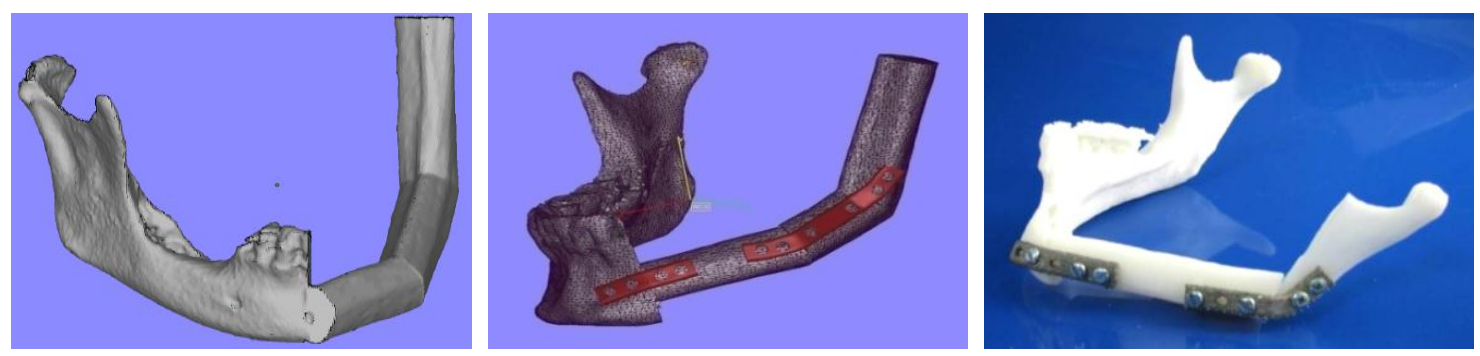

Fig. 3 The process of "virtual reality" planning of the mandible reconstruction surgery, when three sections of the patient's fibula are cut to certain shape and fixed in place by the individually fit fixation plates

Virtual reality image manipulation not only helps to plan the future operation and to generate the files for the preoperational plastic model and fixations plate manufacturing, but also to generate the files for the metal saw guides that would be used to cut the needed bone sections with high precision. Image processing is done using medical $R \& D$ Software package Mimics by Materialise [16] for segmentation and Maya by Autodesk ${ }^{[17]}$ for the implant design. Plastic model is from ABS polymer using FDM $^{\circledR}$ technology, braces- medical titanium, EBM ${ }^{\circledR}$ technology.

Manipulations and modelling of the mechanical properties of the structures in the virtual reality allow for the optimization of functionality and properties of the individually fit metal implants designed using initial medical images. As soon as the CAD file becomes available (Figs. 1b, 2b), it can be used within the software packages common for modelling

structural engineering problems, allowing predicting stress - strain relations, deflections under loads and limiting load values etc. (see, for example, ${ }^{[18-21])}$.

Certain challenges still exist with the sterilization of AM manufactured components intended to be used in the operation theatre. In the $\mathrm{EBM}^{\circledR}$ method, where the parts are built using powerful electron beam in high vacuum at the working area temperatures above 500 and melt zone temperatures exceeding $1000{ }^{\circ} \mathrm{C}{ }^{[3-5]}$, proper part handling 
and traditional sterilization methods are quite adequate and cause no problems. However, sterilization of the plastic preoperative models for their use in the operating theatre is not straightforward. For example, many of the AM methods working with inexpensive polymers, for example, FDM ${ }^{[8-10]}$, are using thermoplastic polymers. Our research shows that traditional sterilization by boiling or hot steaming often significantly distorts the shape of the plastic models manufactured using FDM technology and such models can only be sterilized using cold solutions. Depending on the particular regulations on cold sterilization accepted in the particular countries, it may happen that plastic models sterilized in this way would not be allowed into the operation theatre, being only graded as high-level disinfected. It is still feasible that sterilization of such plastic models can be carried out using hard UV light or ionizing radiation, but these options so far have not been studied.

Today the manufacturing of plastic pre-operative models using AM technology already surpassed the possibilities of the traditional methods of manufacturing in both speed and affordability. Manufacturing of the individually fit solid metal implants is also quite competitive with traditional methods, like 3D milling. In case of medically approved titanium-aluminium- vanadium alloys (for example, Ti6Al4V, ${ }^{[2,3,6,14]}$ ) with proper AM machine loading it is not only faster and less expensive ${ }^{[8]}$, but also less wasteful in material and less energy demanding ${ }^{[22]}$. Our experience shows that with properly organized work process the time from acquiring the medical image until the bone model is delivered to the hospital ranges within 24 to 48 hours (depending on the size and complexity of the models required). Additive manufacturing of the metal implants is slower than the one of plastic models. It can take up 50-70 hrs to design and manufacture the individually fit hip implants in Ti6Al4V alloy using EBM $^{\circledR}$ technology (from acquiring the medical image until the implant can be delivered to the hospital). But practical experience shows, that in complex medical cases when using individually fit implants are among the few options available for the surgeon it is possible to manufacture both the implants and guiding tools (for the saw or drill) in the acceptable period of operation planning and preparation.

In the case of industrial implant manufacturing of the medical implants using $\mathrm{EBM}^{\circledR}$ technology $[14,15]$ it is possible to optimize the manufacturing process, reducing the costs per implant and delivery times. Modern EBM ${ }^{\circledR}$

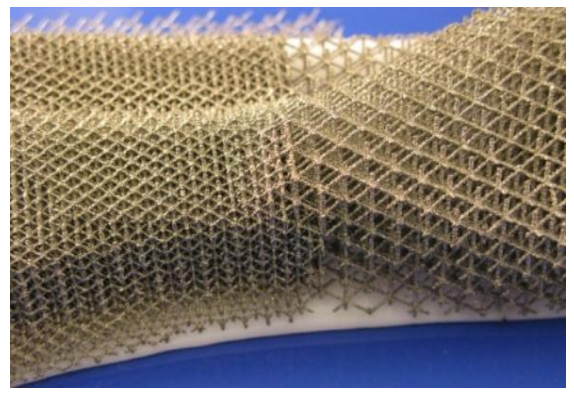

machines can manufacture up to 10-20 different implants at the same time. Therefore, the relative loss of manufacturing time per produced unit due to the machine loading and postprocess cooling is significantly reduced. In addition, with the $\mathrm{EBM}^{\circledR}$ method the manufacturing time for multiple parts in the same batch is not proportional to the number of parts. For example, manufacturing of fourteen different implants in one batch is only fractionally longer than the manufacturing of seven ( 36 and 38 hours of machine operation correspondingly, $\left.{ }^{[13]}\right)$. Image processing and file preparation time increases in similar way, and the material costs are roughly proportional to the weight of the manufactured components. Thus it is possible to significantly decrease overall manufacturing costs per individualised or complex shaped implant in case of AM technologies, as compared to the traditional ways of manufacturing.

\section{LATTICE STRUCTURES}

Advantages of the AM technologies do not stop at manufacturing solid objects conformal to the medical image-defined shapes. For example, the $\mathrm{EBM}^{\circledR}$ process guarantees high quality of the bulk metal together with exceptional flexibility in providing "CAD-to-metal interfacing" and allows manufacturing of the parts combining variable density mesh structures with solid and porous metal in a single manufacturing batch, providing the component shape control to within or even better than 0.1 $\mathrm{mm}^{[3,23-28]}$.

Implants with surface lattice and porosity are reported to have better bone ingrowths and higher stability in the functioning body ${ }^{[23-34]}$. AM technology easily combines mesh structures with different lattice cells and solid parts in the same technological process. Figure 4 shows the section of the part with variable lattice cell sizes (a) and two conformal replicas of the standard hip implant with the stem having conic solid core and lattice with different cell types manufactures using commercial titanium-aluminiumvanadium (Ti6Al4V) EBM $^{\circledR}$ process. Figure 5 provides microphotographs and SEM images of fine lattice structures manufactured in $\mathrm{EBM}^{\circledR}$ technology and an example of their integration into the implant. Note that the cellular structure is manufactured together with the solid part in the same process, and is naturally fused to it in the interface boundary.

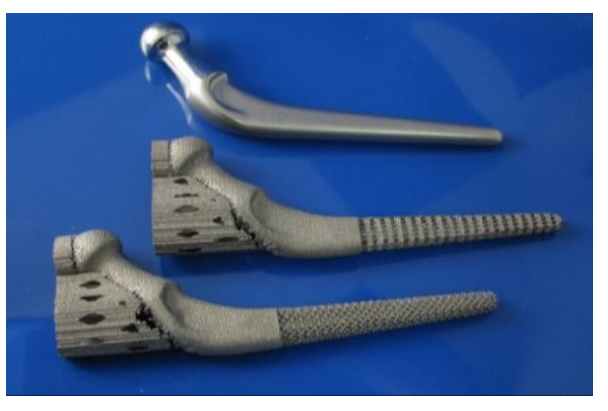

b

Fig. 4 a) Variable lattice cell sizes in the part made from Ti6Al4V using EBM ${ }^{\circledR}$ process b) Standard hip implant (top) and two replicas with lattice on the surface of the stem, as they come out from the $\mathrm{EBM}^{\circledR}$ machine- with service support wafers 
Standard hip implant used as the model is designed to be used with bone cement. In case of the developed net structures on the surface cement bonding to the implant is strongly increased.
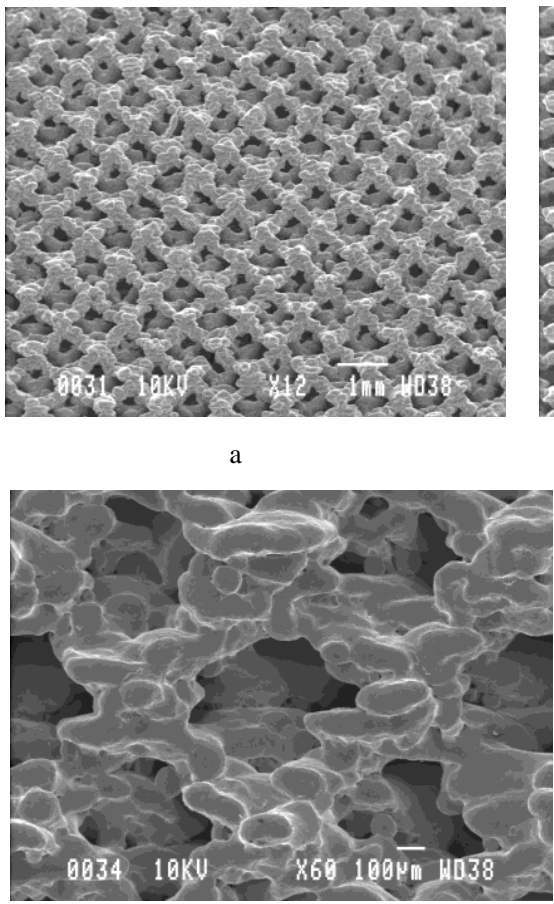

$\mathrm{d}$
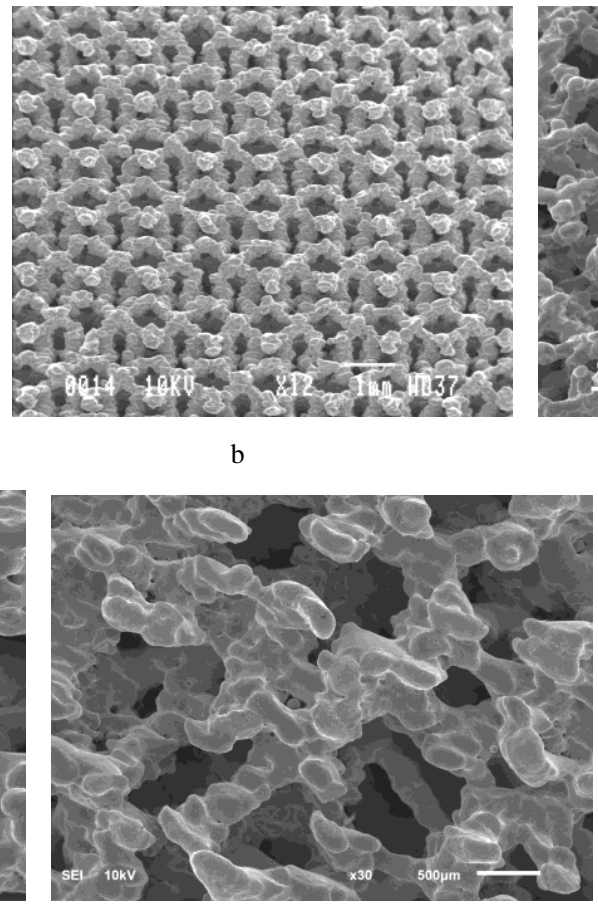

e

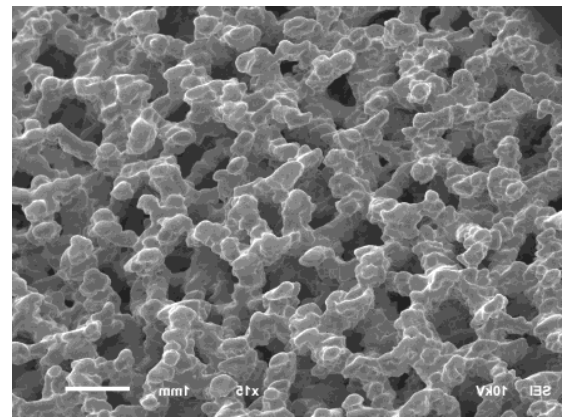

$\mathrm{c}$

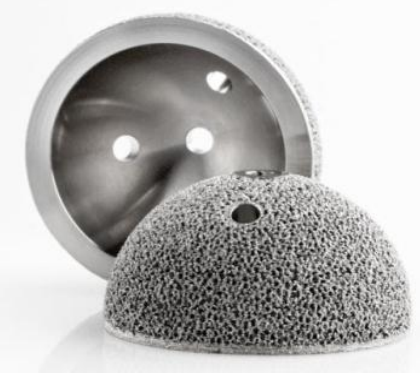

f

Fig. 5 Scanning Electron Mocroscope images of the cellular structures with $1.2 \mathrm{~mm}$ diamond-shaped unit cells (a), $1.2 \mathrm{~mm}$ dodecahedron- shaped cells (b) and "random" cellular structure (c) Higher magnification SEM images of the cellular structures with 1 mm diamond- shaped cells (d) and "random" type cells (e) f) The acetabular cup with solid body and dense random cellular outer surface All made from Ti6Al4V in $\mathrm{EBM}^{\circledR}$ process.

Note that the lattice is by no means limited to the symmetric cell structure. Moreover, by having spatially asymmetric (for example elongated) lattice cells one can manufacture the structures with desired anisotropic mechanical properties, for example stiff in one direction and flexible in two others. Though significant success in using lattice and porosity within $\mathrm{EBM}^{\circledR}$-manufactured structures is

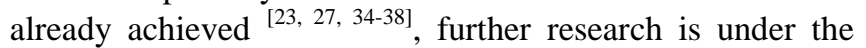
way in many groups across the world. Here the designer inspiration could be taken from the structural studies of strongly anisotropic natural materials like wood, and crystal lattice cells.

Another interesting opportunity exists due to the specifics of the $\mathrm{EBM}^{\circledR}$ process. During the component manufacturing, the deposited thin layer of working powder is first semi-sintered by softer, de-focussed beam ${ }^{[3,4]}$. After sintering, certain parts of the layer are melted by sharply focused beam to yield the solid metal of the parts. Thus after the manufacturing all solid metal sections of the products are surrounded by a semi- sintered metal powder having the consistency of the soft limestone. During the postprocessing, the accessible semi-sintered powder is removed. But it is possible to deliberately design the parts having semi-sintered powder surrounded from all sides by a layer of solid metal ${ }^{[39]}$, thus making a sort of tubular structures with the sintered powder, or lattice core filled with powder inside it. It is known that tubular constructions filled with other materials are much more resistant to buckling as compared to empty tubes ${ }^{[40]}$. The same time implants with the powdered core are much lighter than the solid ones. For example, solid medical grade Ti6Al4V semi-sintered powder has the apparent density of only about $50-60 \%$ of the one of solid metal (similar relations are valid for CoCrMo, another alloy commonly used in the $\mathrm{EBM}^{\circledR}$ process ${ }^{[5,39]}$ ). The same time solid metal shell prevents the undesired contact of the sintered powder inside the implant with the tissue surrounding it in the body.

Cellular structures, manufactured in the AM technology from the polymers, can be used as scaffolding for the growing tissues in the human body ${ }^{[10,11]}$. Here one can also capitalize on the ease of complex shape design and manufacturing characteristic for the AM technologies. Though the polymers traditionally used for additive manufacturing in technology are not certified for medical applications, these methods are well capable of handling the ones certified for biomedical applications ${ }^{[10,41,42]}$. One of the challenging problems here would be the abovementioned sterilization of rather small and fragile parts made of thermoplastic polymers, and the passivation of their surfaces, often being left rather chemically active after the polymerization. But modern manufacturing is used to solving similar problems for the numerous plastic products approved for functioning in contact with human body (see, for example, ${ }^{[43]}$ ). 


\section{SURFACE CONTROL OF METAL IMPLANTS}

In additive manufacturing, $\mathrm{EBM}^{\circledR}$ technology in particular, manufacturing of the features some larger than the average size of the working powder grain is achieved routinely. In the $\mathrm{EBM}^{\circledR}$ process metal structures with well resolved features as small as $0.5-0.2 \mathrm{~mm}$ are already quite common. There are other methods allowing surface feature control to smaller scales, down to $10-100 \mu$, but there are experimental indications that implant surfaces with the micrometer size spatial features in some cases are even more advantageous [7, 39, 44-50]. Controlling the surface features to such high degree of precision in, for example, $\mathrm{EBM}^{\circledR}$ technology is quite challenging due to the process limitations ${ }^{[25]}$. However, certain ways of solving the problems have been already developed. For example using diffused electron beam instead of sharply focused one and varying the process parameters (layer to layer or even within the same layer) it is possible to achieve both bulk and porous metal sections with controlled density and different structure of the pores achieved in the same manufacturing process $[25,39,49]$. But despite serious promises of the improved biocompatibility of the porous metal implants and their increasing practical use the body of conducted research in this area is not yet adequate. Partly it is due to the complexity of the AM process control, partly- to the problems with extracting loose powder grains from the cavities comparable in size, and partly- to the lack of due understanding of the interaction processes between the cells and the implant surface containing the features of different dimensional scales and having complex chemical composition.

Another promising direction is the metal implant surface modification and depositing of bioactive layers during postprocessing ${ }^{[25,35-38,51-64]}$. The main aim of such modifications is to improve the growing bone attachment to the metal surface and the strength of the corresponding interface ${ }^{[44,45]}$. This is achieved through the chemical or electrochemical changes of the metal surface itself, or through depositing the additional layer with higher biocompatibility. Surface modification today is mainly achieved through chemical or electrochemical surface treatment in solutions ${ }^{[25,51-56]}$, in gaseous media ${ }^{[57]}$ or in plasma ${ }^{[58]}$. Electrochemical or chemical processing in liquid solutions (Figure 6) is more favourable as it does not need costly equipment. On the other hand, plasma based methods are much more effective for the uniform surface modification of the dense lattice and porous structures, where solution-based methods have problems in reaching deep inside the small holes. As to the coating of the metal implants, it has already evolved into a separate research and development area, where both inorganic (like calcium phosphates or hydroxyapatite, see, for example, ${ }^{[59-61]}$ ) and organic (for example, biopolymers ${ }^{[63]}$ ) compounds. One of the challenges with the implant surface coating is the uniformity of the coating of the lattice structure through all of its depth ${ }^{[25,62]}$.

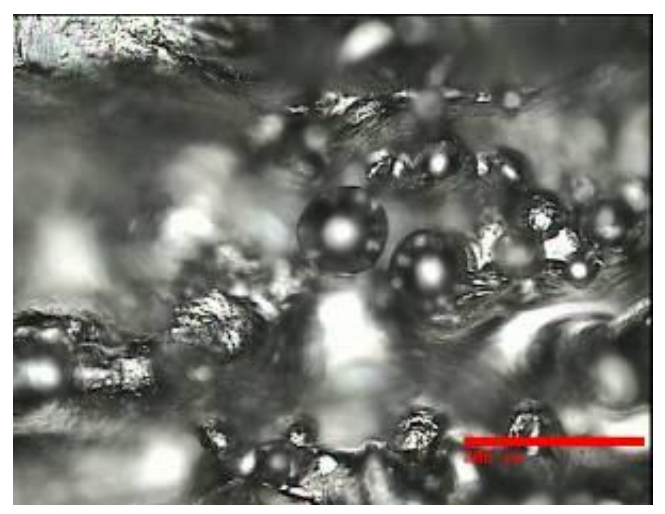

a

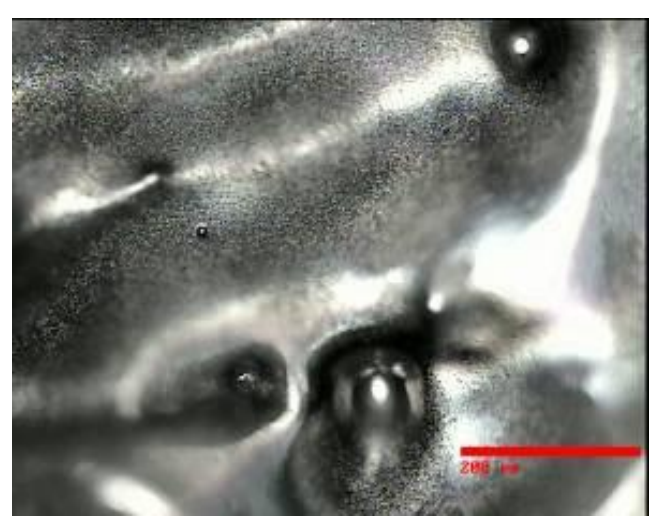

$\mathrm{b}$

Fig. 6 Microphotographs of the surface of the Ti6Al4V cellular structure as it comes after manufacturing (a) and electrochemically etched for 40 minutes at $30^{\circ} \mathrm{C}$ with the $6 \mathrm{~A} / \mathrm{dm}^{2}$ current density in the 2-propanol ethanol non-aqueous electrolytic solution of $\mathrm{ZnCl}_{2}$ and $\mathrm{AlCl}_{3}$ (for more details see ${ }^{[24,58]}$ )

Etching conditions are optimised for the removal of the surface structures below 50-70 $\mu$. Marker bar on the photographs is $200 \mu$.

\section{IMPLANT FIXATION}

Long term implant stability in the body is a very serious concern influencing both the design, production and postprocessing stages of implant manufacturing. The ultimate solution of the problem can be found through the application of a set of measures targeting faster and better integration of the implant into the surrounding tissue. It inevitably means that implants should be not only be optimized in shape and have mechanical properties similar to the ones of the body parts they substitute or reinforce, but have the proper surface micro- geometry and chemical composition.

As discussed earlier, modern AM technology allows optimization of the implant shape and with certain postprocessing can achieve improved osseointegration at the early stages. The same time significant research efforts are devoted to the strengths of the interface between the live tissue and implant ${ }^{[44,65]}$. One of the particular problems here lays in significant difference of mechanical properties of the metal implant, bone cement or implant surface coating and surrounding tissue. For example, it is suggested that many problems with traditional solid hip stem implants becoming loose with the time is due to the reduction of the 
bone density (stress shielding ) and even direct loss of the bone mass around the implant. It is mainly attributed to the significant and varying stresses caused in the interface by the normal functioning of the human body ${ }^{[66-72]}$. Proper computer modelling of the mechanical properties of the implant sitting in its place allows generating optimised designs with demanded functionality and reduced stress shielding, still keeping the desired shape outlines generated from the medical images. This can be achieved by using inhomogeneous cellular structures in the implant construction ${ }^{[73]}$. Manufacturing of such implants is well within the possibilities of the modern additive manufacturing, but is hardly feasible with any other technology. Another serious problem occurs with the patients having weakened bones that can hardly sustain any solid metal implant on their own. Using additional strong and lightweight metal cages (Fig. 7) made using AM technologies can reinforce the bones and significantly improve the chances for successful implant integration. Other contributing factors that could facilitate the reduction in bone density are the ionic activity of the uncoated metal surface and obvious restriction in the nutrient circulation in the interface zone. Better understanding of the influence of these factors can be achieved, for example, through thorough proper modelling of the nutrient transport process and bone remodelling ${ }^{[74,75]}$.
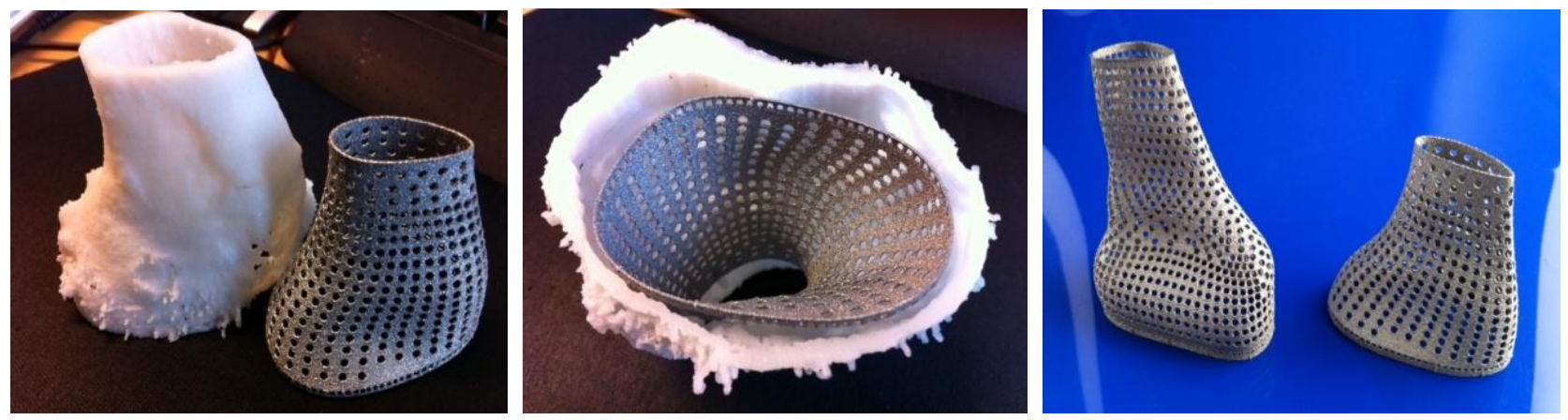

Fig. 7 Metal cages made from medical grade Ti6Al4V using EBM ${ }^{\circledR}$ technology are designed to reinforce the patient's femur, ready to accommodate traditional knee replacement implant

Interesting discussion is going over the issue, which is more advantageous; having tightly, fit implants without bone cement, or loosely fit using some bone cement ${ }^{[76]}$. Nevertheless, from the engineering point of view neither option is perfect, as one is attempting to create strong adhesive interfaces between the materials with significantly different elastic and thermal properties. One of the effective solutions to this problem is known to engineers, it lies with using composite materials ${ }^{[77,78]}$. This approach is also gaining its positions in the applications to the biomedical implants ${ }^{[79-83]}$. Composite materials are widely used in modern technology because they often possess unique properties not available for any of the separate materials, combining flexibility and stress resistance ${ }^{[82]}$ ), providing materials with gradually changing properties etc. For example, using AM technologies one can easily manufacture the metal reinforcing structures that could be filled with bone cement in the removable formwork technology similar to the cast-in-situ reinforced concrete used in the construction industry. Metal reinforcement is known to increase the tensile strength of the cast parts, and is used to safely anchor the future solid cast in place. The same time by using anisotropic cell metal lattices as reinforcement material one can achieve desired anisotropic mechanical properties of the resulting composites. This technology can be used, for example, for substituting missing bone fragments. To our knowledge, this interesting opportunity so far has not been properly explored.

An interesting opportunity is inspired by the known hydroxiapatite- filled bone cement ${ }^{[78,83]}$. It is often hard to get a strong bond between the untreated metal implant surface and the deposited calcium phosphates, hydroxiapatite in particular ${ }^{[44,65]}$. But if the implant surface is covered by a thin layer of curing bone cement and "dusted" by the hydroxiapatite flakes it forms a stable coating with very high biocompatibility. For example, when manufacturing metal implants using the $\mathrm{EBM}^{\circledR}$ technology it is relatively easy to control the part features at macro- and micro- scale. By using composite bone cement and hydroxiapatite composite coatings of the metal implants one can achieve also high degree of control over the micro- and nano- porosity over the surface coating composite in relatively simple technology. But to our knowledge the possibilities opened by using the composites containing metal reinforcing lattices, polymers and hydroxiapatite are not properly explored yet.

\section{NEW MATERIALS}

The development of the AM technologies historically has been mainly driven by engineering applications. Biomedical applications are one of the recent areas where the advantages of these technologies can be exploited in full. So this application area is now attracting more and more attention of the technology developers. Comprehensive review of the particular subject of new materials becoming available for the AM technologies is far beyond the scope of present paper. But one of the most intriguing opportunities becoming available to the AM technologies deserves specific mentioning. This opportunity is additive manufacturing in amorphous or glassy metals ${ }^{[84]}$. These are complex alloys with unique mechanical properties, record high tensile strength, high toughness, good corrosion resistance, good processability and good biocompatibility ${ }^{[85-87]}$. All these features are in strong demand by traditional technological applications, but they are also beneficial to the bio-medical applications, implant manufacturing in 
particular. Combining unique properties of the new material with the freedom of shape forming of AM technologies was a very promising pathway for the research and development. First success is already achieved in this direction applying selective laser sintering ${ }^{[88]}$ of the Pt-based alloy, and in our laboratory, using $\mathrm{EBM}^{\circledR}$ process and so called Colferoloy, iron- based amorphous alloy by Wall Colmonoy Ltd ${ }^{[89]}$. Significant interest to the iron-based bulk metallic glass alloys is determined by their lower cost as compared to the other known amorphous alloys often containing platinum or rare earth elements ${ }^{[84-88]}$. Also the iron based alloys are generally safer in manufacturing as compared to other amorphous alloys (for example the Zr-based ones ${ }^{[84,85,87]}$ ).

\section{INSTEAD OF THE CONCLUSION}

Additive manufacturing is a rapidly evolving family of modern technologies. Parts manufactured using AM technologies are strongly gaining the acceptance of practical surgeons. The number of companies, having additive manufacturing of the metal implants for orthopaedics and dentistry as their core business also increases quite rapidly. Our experience shows, that after getting access to the AM technology of medical implant and pre-operative models manufacturing practical doctors are quite happy to use these technologies on the regular basis. But so far the general awareness of the possibilities already available with additive manufacturing technologies with practical medics is relatively low. So certain efforts should be made to assure that additive manufacturing of the metal medical implants and pre-operative models will gradually become an everyday tool of modern practical surgery.

Also, existing regulations on the medical implant manufacturing in some sense are aiming towards standardization of the implant shapes and sizes. This is not surprising as they were compiled before the semi-industrial manufacturing of individually fitted medical implants became a reality. Thus certain efforts should also be made by practical medicine and technology together in helping the regulatory bodies in modifying these regulations to allow for the opportunities provided by the AM technologies.

\section{REFERENCES}

[1] J.J. Beaman, C. Atwood, T.L. Bergman, D. Bourell, S.Hollister, and D. Rosen, "Additive/ Subtractive Manufacturing Research and Development in Europe" (WTEC Panel Report), Available online: www.wtec.org/additive/report/additive-report.pdf.

[2] Z. Czajkiewicz, A. Sirinterlikci, and O. Uslu, "Rapid manufacturing: The future of production systems," Proc. 2007 American Society for Engineering Education (ASEE) Conference, 2007, $\quad$ p. 65 . http://www.icee.usm.edu/ICEE/conferences/asee2007/papers/ 65_RAPID_MANUFACTURING__THE_FUTURE_OF_P ROD.pdf.

[3] P. Heinl, C. Körner, and R. F. Singer, "Selective Electron Beam Melting of Cellular Titanium: Mechanical Properties," Advanced Engineering Materials, vol. 10, pp. 882-8, 2008.

[4] ARCAM AB, company website: http://www.arcam.com.
[5] M. Larsson, U. Lindhe, and O. Harrysson, "New Specification for Additive Manufacturing Titanium-6 Aluminum-4 Vanadium with Powder Bed Process," in Proc. 14th Solid Freeform Fabrication (SFF) symposium, Austin, Texas, August 2003, pp. 433-8, 2003.

[6] ASTM WK30522: "New Specification for Additive Manufacturing Titanium-6 Aluminum-4 Vanadium with Powder Bed Process", http://www.astm.org/DATABASE.CART/WORKITEMS/W K30522.htm.

[7] A. Bandyopadhyay, F. España, V. K. Balla, S. Bose, Y. Ohgami, and N. M. Davies, "Influence of porosity on mechanical properties and in vivo response of Ti6Al4V implants," Acta Biomater., vol. 6 (4), pp. 1640-8, 2010, Epub. Nov 12, 2009.

[8] Stratasys 3D Printers and 3D Production Systems, http://www.stratasys.com, http://www.stratasys.com/Products.aspx.

[9] Objet Ltd, http://www.objet.com/3DPrinter/Products_Overview/.

[10] S. Lohfeld, V. Barron, and P. E. McHug, "Biomodels of bone: a review”, Ann Biomed Eng., vol. 33 (10), pp 1295-311, Oct. 2005.

[11] S. J. Hollister, R. D. Maddox and J. M. Taboas, "Optimal design and fabrication of scaffolds to mimic tissue properties and satisfy biological constraints," Biomaterials, vol. 23 (20), pp. 4095-4103, October 2002.

[12] Open Source Project Fab@Home, http://www.fabathome.org.

[13] M. Cronskär, L.-E. Rännar, M. Bäckström, and A. Koptyug, "Application of electron beam melting to titanium hip stem implants “, in: Proc Intl Conference on Additive Technologies, Vienna, DAAAM International, p. 1559, 2008.

[14] A. Christensen, A. Lippincott, and R. Kircher, "An Introduction to Electron Beam Melting with Ti6Al4V-ELI for the Orthopaedic Device Industry," BONEZone, vol. 6, pp 1417, 2007.

[15] ADLER-ALA ORTHO group, http://www.alaortho.com; Lima Corporate, http://www.lima.it/;Medical Modeling, http://www.medicalmodeling.com.

[16] Materialise, Medical R\&D Software package Mimics,Company web site: http://www.materialise.com/BiomedicalRnD.

[17] Software package Maya, Autodesk, http://usa.autodesk.com/maya/.

[18] N. E. Emerson, M.J. Carre, G. C. Reilly, and A. O. Offiah, "Geometrically accurate 3D FE models from medical scans created to analyse the causes of sports injuries", Procedia Engineering, vol. 13, pp.422-7, 2011.

[19] Software package SolidWorks, Dassault Systèmes SolidWorks Corp., Company web site: www.solidworks.com/.

[20] L. B. Zhou, H. T. Shang, L. S. He, B. Bo, G. C. Liu, Y. P. Liu, and J. L. Zhao, "Accurate reconstructionof discontinuous mandible using a reverse engineering/computer-aided design/rapid prototyping technique: a preliminary clinical study," Journal of Oral and Maxillofacial Surgery, vol. 68, pp. 2115-21, 2010.

[21] M. Cronskär, "The Use of Additive Manufacturing in the Custom Design of Ortopedic Implants", Lic. Thesis, Mid Sweden University, 2011, ISBN 978-91-86694-42-5, available online: http://miun.divaportal.org/smash/record.jsf?pid=diva2:436633. 
[22] M. Tuck, C. Hague, I. Ashcroft, and R. Wildman, "A comparative study of metallic additive manufacturing power consumption", Proc. Solid Freeform Fabrication Symposium, Austin, USA, 8-10 Aug. 2010, pp. 278-288, 2010.

[23] L. E. Murr, S. M. Gaytan, F. Medina, H. Lopez, E. Martinez, B. I. Machado, D. H. Hernandez, L. Martinez, M. I. lopez, R. B. Wiker, and J. Bracke, "Next-generation biomedical implants using additive manufacturing of complex, cellular and functional mesh arrays", Phil. Trans. Roy. Soc. A, vol. 368, pp. 1999-2032, 2010.

[24] P. Heinl, L. Müller, C. Körner, R. F. Singer, and F. A. Müller, "Cellular Ti-6Al-4V structures with interconnected macro porosity for bone implants fabricated by selective electron beam melting," Acta Biomaterialia, vol. 4 (5), pp. 1536-44, 2008.

[25] A. Koptyug, L. E. Rännar, M. Bäckström, and R. P. Klingvall, "Electron Beam Melting: Moving from Macro- to Micro- and Nanoscale," Materials Science Forum vol. 706-709, pp 532537, 2012, Ed. T. Chandra, M. Ionescu and D. Mantovani.

[26] T. Nakano, W. Fujitani, T. Ishimoto, J.-W. Lee, N. Ikeo, H. Fukuda, and K. Kuramoto, "Formation of New Bone with Preferentially Oriented Biological Apatite Crystals Using a Novel Cylindrical Implant Containing Anisotropic Open Pores Fabricated by the Electron Beam Melting (EBM) Method," ISIJ International, vol. 51 (2), pp.262-8, 2011.

[27] G. M. de Peppo, A. Palmquist, P. Borchardt, M. Lennerås, J. Hyllner, A. Snis, J. Lausmaa, P. Thomsen, and C. Karlsson, "Free-Form-Fabricated Commercially Pure Ti and Ti6Al4V Porous Scaffolds Support the Growth of Human Embryonic Stem Cell-Derived Mesodermal Progenitors," The Scientific World Journal, vol. 2012, Article ID 646417, 2012.

[28] J. Parthasarathy, B. Starly, S. Raman, and A. Christensen, "Mechanical evaluation of porous titanium (Ti6Al4V) structures with electron beam melting (EBM)," Journal of the Mechanical Behavior of Biomedical Materials, vol. 3 (3), pp. 249-59, 2010.

[29] J. P. Li, P. Habibovic, M. van den Doel, C. E. Wilson, J. R. de Wijn, C. A. van Blitterswijk, and K. de Groot, "Bone ingrowth in porous titanium implants produced by $3 \mathrm{D}$ fiber deposition," Biomaterials, vol. 28 (18), pp. 2810-20, 2007.

[30] K. Alvarez, and H. Nakajima, "Metallic scaffolds for bone regeneration," Materials, vol. 2, pp. 790-832, 2009.

[31] G. E. Ryan, A. S. Pandit, and D. P. Apatsidis, "Porous titanium scaffolds fabricated using a rapid prototyping and powder metallurgy technique," Biomaterials, vol. 29 (27), pp. 3625-35, 2008.

[32] L. Mullen, R. C. Stamp, W. K. Brooks, E. Jones, and C. J. Sutcliffe, "Selective laser melting: a regular unit cell approach for the manufacture of porous, titanium, bone in-growth constructs, suitable for orthopedic applications," Journal of Biomedical Materials Research B, vol. 89 (2), pp. 325-34, 2009.

[33] I. V. Shishkovsky, L. T. Volova, M. V. Kuznetsov, Y. G. Morozov, and I. P. Parkin, "Porous biocompatible implants and tissue scaffolds synthesized by selective laser sintering from Ti and NiTi," Journal of Materials Chemistry, vol. 18 (12), pp. 1309-17, 2008.

[34] E. J. ten Hallers, J. A. Jansen, H. A. Marres, G. Rakhorst, and G. J. Verkerke, "Histological assessment of titanium and polypropylene fiber mesh implantation with and without fibrin tissue glue," J Biomed Mater Res A, vol. 80 (2), pp. 372-80, 2007.
[35] S. Ponader, E. Vairaktaris, P. Heinl, C. von Wilmowsky, A. Rottmair, C. Körner, R.F. Singer, S. Holst, K.A. Schlegel, F.W. Neukam, and E. Nkenke, "Effect of topographical surface modifications of Electron Beam Melted Ti-6Al-4V titanium on human fetal osreoblats," Journal of Biomedical Research A, vol.84A(4), pp. 1111-19, 2007.

[36] P. Heinl, A. Rottmair, C. Körner, and R. F. Singer, "Cellular titanium by selective electron beam melting," Advanced Engineering Materials, vol. 9 (5), pp. 360-4, 2007.

[37] U. Muller, T. Imwinkelried, M. Horst, M. Sievers, and U. Graf-Hausner, "Do human osteoblasts grow into open-porous titanium?" European Cells and Materials, vol. 11, pp. 8-15, 2006.

[38] S. Fujibayashi, M. Neo, H. M. Kim, T. Kokubo, and T. Nakamura, "Osteoinduction of porous bioactive titanium metal," Biomaterials, vol. 25 (3), pp. 443-450, 2004.

[39] F. A. España, V. K. Balla, S. Bose, and A. Bandyopadhyay, "Design and fabrication of CoCrMo alloy based novel structures for load bearing implants using laser engineered net shaping," Materials Science \& Engineering C, vol. 30 (1), pp. 50-7, January 2010.

[40] A. N. Kounadis, and X. A. Lignos, "Buckling of tube-like shells filled with other material under uniform axial compression,” Engineering Structures, vol. 22 (8), pp/ 961-7, June 2000.

[41] G. Lewis, "Properties of the Acrylic Bone Cement: State of the Art Review," Journal of Biomedical Materials Research, vol. 38 (2), pp. 155-182, 1997.

[42] G. Zambonin, S. Colucci, F. Cantatore, and M. Grano, "Response of Human Osteoblasts to Polymethylmetacrilate in Vitro," Calciofied Tissue Internationsl, vol. 62 (4), pp 362365, 1998.

[43] A. Gupta, "Controlled surface optical lens and method of surface alteration," US patent $\mathrm{Nr}$ 5274038, December 28, 1993.

[44] K. A. Thomas, and S. D. Cook, "An evaluation of variables influencing implant fixation by direct bone apposition," J Biomed Mater Res. vol. 19 (8), pp. 875-901, October 1985.

[45] M. Franchi, M. Fini, D. Martini, E. Orsini, L. Leonardi, A. Ruggeri, G. Giavaresi, and V. Ottani, "Biological fixation of endosseous implants," Micron Oxford England 1993, vol. 36 (7-8), pp. 665-671, 2005.

[46] R.K. Alla, K. Ginjupalli, N. Upadhya, M. Shammas, R. K. Ravi, and R. Sekhar, "Surface Roughness of Implants: A Review," Trends Biomater. Artif. Organs, vol. 25 (3), pp. 112-8, 2011.

[47] A. Wennerberg, and T. Albrektsson, "Current challenges in successful rehabilitation with oral implants," Journal of Oral Rehabilitation, vol.38 (4), pp. 286-94, April 2011.

[48] A. Palmquist, F. Lindberg, L. Emanuelsson, R. Branemark, H. Engqvist, and P. Thomsen, "Biomechanical, histological, and ultrastructural analyses of laser micro- and nano-structured titanium alloy implants: a study in rabbit," Journal of Biomedical Materials Research A, vol. 92 (4), pp. 1476-86, 2010.

[49] A. Palmquist, O.M. Omar, M. Esposito, J. Lausmaa and P. Thomsen, "Titanium oral implants: surface characteristics, interface biology and clinical outcome," J. R. Soc. Interface, vol. 7, pp. S515-27, 2010. 
[50] K. H. Frosch and K. M. Stürmer, "Metallic biomaterials in skeletal repair,” Eur J Trauma Emerg S, vol. 32, pp. 149-59, 2006.

[51] T. Hanawa, "In vivo metallic biomaterials and surface modification," Mater Sci Eng, vol. A267, pp. 260-6, 1999.

[52] H. Daugaard, B. Elmengaard, J. E. Bechtold, and K. Soballe, "Bone growth enhancement in vivo on press-fit titanium alloy implants with acid etched microtexture," J. Biomed. Mater. Res. A, vol 87, pp. 434-40, 2008.

[53] K. H. Kim, and N. Ramaswamy, "Electrochemical surface modification of titanium in dentistry," Dent Mater J., vol. 28 (1), pp. 20-36, January 2009.

[54] T. Kokubo, T. Matsushita, H. Takadama, T. Kizuki, "Development of bioactive materials based on surface chemistry," Journal of the European Ceramic Society, vol. 29 (7), pp. 1267-74, 2009.

[55] B. Yang, M. Uchida, H.-M. Kim, X. Zhanga, and T. Kokubo, "Preparation of bioactive titanium metal via anodic oxidation treatment," Biomaterials, vol. 25, pp. 1003-10, 2004.

[56] K. Tajima, M. Hironaka, K.-K. Chen, Y. Nagamatsu, H. Kakigawa and Y. Kozono, "Electropolishing of CP titanium and its alloys in an alcoholic solution-based electrolyte," Dent Mater J, vol. 27 (2), pp. 258-65, 2008.

[57] M. Navarro, A. Michiardi, O. Castaño, and J. A. Planell, "Biomaterials in Orthopaedics," J. R. Soc. Interface, vol 5, pp. 1137-58, 2008.

[58] E. R. Parker, B. J. Thibeault, M. F. Aimi, M. P. Rao, and N. C. MacDonald, "Inductively Coupled Plasma Etching of Bulk Titanium for MEMS Applications," J Electrochem Soc, vol. 152 (10), p. C675, 2005.

[59] R. Narayanan, S. R. Seshadri, T. Y. Kwon, and K. H. Kim, "Calcium phosphate-based coatings on titanium and its alloys," J Biomed Mater Res B Appl Biomater., vol. 85 (1), pp. 279-99, April 2008.

[60] W. Singhatanadgit, "Biological Responses to New Advanced Surface Modifications of Endosseous Medical Implants," Bone and Tissue Regeneration Insights, vol. 2, pp. 1-11, 2009.

[61] G. X. Ni, Y. S. Choy, W. W. Lu, A. H. Ngan, K. Y. Chiu, Z. Y. Li, B. Tang, and K. D. Luk, "Nano-mechanics of bone and bioactive bone cement interfaces in a load-bearing model," Biomaterials, vol. 27 (9), pp. 1963-70, 2006.

[62] J. W. Vehof, P. H. Spauwen, and J. A. Jansen, "Bone formation in calcium-phosphate-coated titanium mesh," Biomaterials, vol. 21 (19), pp. 2003-9, 2000.

[63] B. Nebe, M. Cornelsen, A. Quade, V. Weissmann, F. Kunz, S. Ofe, K. Schroeder, H. Seitz, and C. Bergemann, "Osteoblast Behavior In Vitro in Porous Calcium Phosphate Composite Scaffolds, Surface Activated with a Cell Adhesive Plasma Polymer Layer," Materials Science Forum, vol. 706-709, pp. 566-571, 2012, Ed. T. Chandra, M. Ionescu and D. Mantovani.

[64] R. Ma, and I. Zhitomirsky, "Electrophoretic Deposition of Organic- Inorganic Composites for Biomedical Applications," Materials Science Forum, vol. 706-709, pp. 617-622, 2012, Ed. T. Chandra, M. Ionescu and D. Mantovani.

[65] D. J. Blackwood, K. H. Seah, "Influence of anodization on the adhesion of calcium phosphate coatings on titanium substrates," J Biomed Mater Res A., vol. 93 (4), pp. 1551-6, June 2010 .

[66] M. J. Grimm, "Selection of Materials for Biomedical Applications" in: Handbook of Materials Selection, Ed. M. Kutz, M. J. Grimm, John Wiley \& Sons, New York, 2002.
[67] H. W. J. Huiskes, H. Weinans, and B. van Rietbergen, "The Relationship Between Stress Shielding and Bone Resorption Around Total Hip Stems and the Effects of Flexible Materials," Clin. Orthop., vol. 274, pp. 124-34, 1992.

[68] M. Niinomi, and M. Nakai, "Titanium-Based Biomaterials for Preventing Stress Shielding between Implant Devices and Bone," International Journal of Biomaterials, vol. 2011, Article ID 836587, 2011, Epub. June 22, 2011.

[69] J. Li, H. Li, L. Shi, A. S. L. Fok, C. Ucer, H. Devlin, K. Horner, and N. Silikas, "A mathematical model for simulating the bone remodeling process under mechanical stimulus, Dental Materials, vol. 23, pp. 1073-78, 2007.

[70] B.-A. Behrens, C. J. Wirth, H. Windhagen, I. Nolte, A. Meyer-Lindenberg, and A. Bouguecha, "Numerical investigations of stress shielding in total hip prostheses," Proceedings of the Institution of Mechanical Engineers, Part H: Journal of Engineering in Medicine, vol. 222 (5), pp. $593-$ 600, May 2008.

[71] D. R. Carter, R. Vasu, and W. H. Harris, "Stress distributions in the acetabular region--II. Effects of cement thickness and metal backing of the total hip acetabularcomponent", J Biomech., vol. 15 (3), pp. 165-70, 1982.

[72] J. M. S. Lamvohee, R. Mootanah, P. Ingle, K. Cheah, and J. Dowell, "Total hip replacement: Effect of cement mantle thickness on the stability of acetabular cups, using finite element methods", in: Proc. of the 5th Australasian Biomechanics conference, p. 10, 2004.

[73] K. Ścigała, R. Bedziński, J. Filipiak, E. Chlebus, B. Dybała, "Application of generative technologies in the design of reduced stiffness stems of hip joint endoprosthesis", Archives of Cyvil and Mechanical Engineering, vol. XI 2011 (3), pp. 753-67, 2011.

[74] T. Lemaire, S. Naili, and V. Sansalone, "Multiphysical modelling of fluid transport through osteo-articular media," Anais da Academia Brasiliera de Ciências (Annals of the Brasilian Academy of Sciences) vol. 82, p. 127, 2010.

[75] D. Lin, Q. Li, W. Li, and M. Swain, "Bone Remodeling Induced by Dental Implants of Functionally Graded Materials," J Biomed Mater Res B Appl Biomater., vol. 92 (2), pp. 430-8, February 2010.

[76] B. J. A. Lankester, J. Stoney, S. Gheduzzi, A. W. Miles, and G. C. Bannister, "An in-vitro evaluation of optimal acetabular cement mantle thickness", J Bone Joint Surg.Br., vol. 86-B, Suppl. 1, pp. 75-76, 2004.

[77] R. B. Grubbs, "Hybrid Metal-Polymer Composites from Functional Block Copolymers," Journal of Polymer Science Part A: Polymer Chemistry, vol. 43 (19), pp. 4323-36, 2005.

[78] S. M. Zebarjad, S. A Sajjadi, T. Ebrahimi Sdrabadi, S. A Sajjadi, A. Yaghmaei, and B. Naderi, "A Study on Mechanical Properties of PMMA/Hydroxyapatite Nanocomposite," Engineering, vol. 3 (8), pp. 795-801, August 2011.

[79] C. Ohtsuki, "Development of bioactive organic-inorganic hybrid for bone substitutes," Materials Science and Engineering C, vol. 22 (1), pp. 27-34, 2002.

[80] S. Jyoti, S. Bose, H. L. Hosick, and A. Bandyopadhyay, "Development of controlled porosity polymer-ceramic composite scaffolds via fused deposition modeling," Materials Science and Engineering C, vol. 23 (5), pp. 611-20, 2003.

[81] S. Kalita, J. Finley, S. Bose, H. Hosick and A. Bandyopadhyay, "Development of Porous Polymer-Ceramic 
Composites as Bone Grafts,” in: Proc. Mat. Res. Soc. Symp. , vol. 726, Q5.8, 2002.

[82] I. Knets, V. Krilova, R. Cimdins, L. Berzina, and V. Vitins, "Stiffness and strength of composite acrylic bone cements," Journal of Achievements in Materials and Manufacturing Engineering (JAMMIE), vol. 20 (1-2), pp. 135-8, JanuaryFebruary 2007.

[83] Q. Liu, "Hydroxyapatite/polymer composites for bone replacement", Doctoral Thesis, University of Twente, The Netherlands, May 1997, available online: http://purl.utwente.nl/publications/58693.

[84] W. H. Wang, C. Dong, and C. H. Shek, "Bulk metallic glasses," Materials Science and Engineering Reports, vol. 44 pp. 45-89, 2004.

[85] J. Schroers, G. Kumar, T. M. Hodges, S. Chan, and T. R Kyriakides, "Bulk metallic glasses for biomedical applications", Journal of the Minerals, Metals and Materials Society, vol. 61 (9), pp. 21-9, 2009,
http://resolver.caltech.edu/CaltechAUTHORS:20100304142135154

[86] F. Qin, Z. Dan, X. Wang, G. Xie, and A. Inoue, "Ti-Based Bulk Metallic Glasses for Biomedical Applications," in: Biomedical Engineering, Trends in Materials Science, Ed. Anthony N. Laskovski, Publisher: InTech, January, 2011.

[87] L. Huang, Z. Cao, H. M. Meyer, P. K. Liaw, E. Garlea, J. R. Dunlap, T. Zhang, and W. He, "Responses of bone-forming cells on pre-immersed Zr-based bulk metallic glasses: Effects of composition and roughness," Acta Biomater., vol. 7 (1), pp. 395-405, Jan 2011; Epub. Aug 13, 2010.

[88] P. Fischer; A. Blatter; V. Romano; H.P. Weber, "Selective laser sintering of amorphous metal powder," Applied Physics A, vol. 80 (3), February 2005.

[89] Wall Colmonoy

Ltd, http://www.wallcolmonoy.co.uk/products-services/colferoloy$\%$ c2\%ae/. 